\title{
INDOOR CLIMATE SIMULATION IN A CHURCH DURING WINTER SEASON
}

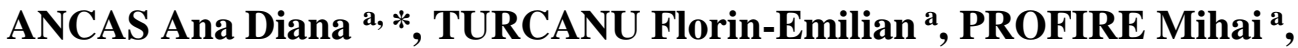 VERDES Marina ${ }^{a}$, BALAN Marius Costel a}

\author{
a Technical University "Ghe. Asachi" of Iasi, Faculty of Civil Engineering and Building Servicies, Department Building Sevicies, D. \\ Mangeron 67 str., 700050, Romania, e-mail: ancas05@yahoo.com
}

Received: 21.02.2019 / Accepted: 23.03.2019/ Revised: 25.04.2019 / Available online: 31.05.2019

DOI: 10.2478/jaes-2019-0003

KEY WORDS: hydronic heating systems, indoor climate modelling, thermal comfort.

\begin{abstract}
:
In the paper is presented a heating system installed in church and the interior climate generated. Thermal Comfort is the purpose of each designer, since the design stage and has to be ensure for the churchgoers, but even for the interior finishes. The heating system that uses hydronic radiators is evaluated trough the CFD modelling, in order to evaluate pro and contra arguments. The simulation has been made in a $3 \mathrm{~d}$ simulation software environment, in Autodesk CFD with good results.
\end{abstract}

\section{INTRODUCTION}

The indoor microclimate that's has been analysed is found in the church of Saint Cross Rising, in the village of Săbăoani, country of Neamț (Figure 1a). The church has been built in the years of 2000, on a mixt structure of masonry and columns and girders of reinforced concrete. At the top the church has a dome made from reinforced concrete. The heating system is formed by a hydronic radiator systems and a boiler with the power of $40 \mathrm{~kW}$, that burn wood. The heating systems is mounted on the exterior walls under the windows (Figure 1b).

Church is formed by a single shape nave, with the opening of 13,5 meters and a total height of 14 meters. Also the total length is of 23 meters, this numbers gives a total heating volume for the church of $3000 \mathrm{~m}^{3}$ (Figure $2 \mathrm{a}, \mathrm{b}$ ).

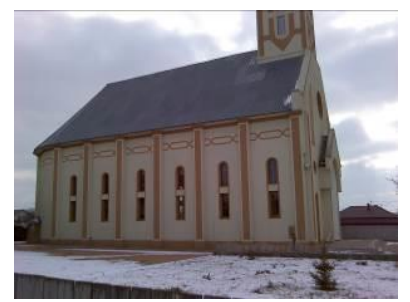

a

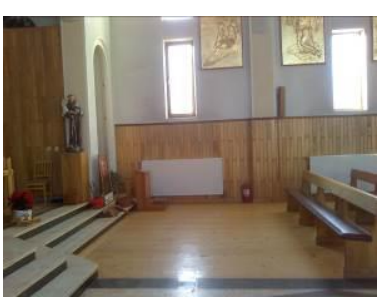

b
Figure 1. a) Exterior view of the studied church b) Existing heating system inside the church

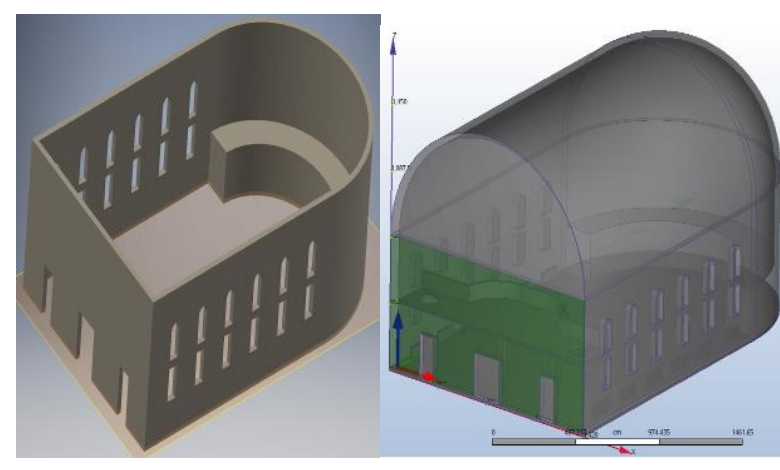

a

b

Figure 2. a) ,b) View of the church from the modelling process

Exterior walls have the weight of 0.4 meters, covered with a layer of 0.05 meters of polystyrene insulation and the exterior windows are made from insulated glass with woodwork made from PVC.

To create an indoor climate, distinct from the outside one, is the main purpose for almost all buildings and in our case for worship buildings. Also the climate created in the churches provides the thermal comfort for the churchgoers. By controlling the parameters that generate the indoor climate leads to an appropriate and sustainable use of the energy resources with a high costefficiency management. (Schellen and Lambertus, 2002, Sen, 2008).

In the current practice of heating systems that lead to the creation of the indoor climate in churches, the technical solution are

\footnotetext{
* Corresponding author: ANCAS Ana Diana, e-mail: ancas05@yahoo.com
} 
always a reference, meanwhile the real difficulties are choosing the criteria that form a suitable climate. That is why the literature refers to the following parameters when it comes to the indoor thermal climate of the places of worship: 1. Air temperature; 2. Surface Temperature; 3. Relative humidity; 4. Displacement of Air Currents (Sen, 2008, Vuerich, 2008).

In order to understand how we can control the indoor microclimate in the places of worship, there is a need for a physical and also quantitative understanding of the complex interaction that exists between the above mentioned parameters (Varas Muriel et al., 2014).

\section{MODELLING INDOOR MICROCLIMATE}

CFD modelling based on FVM (Finite Volume Methods) has opened the way for solving moment, mass and energy equations. Also, the k-e turbulence model and a standard model to define the wall flow, created the premises for dynamics simulations with a high degree of trust for thermal modelling of the interior climate, air movements etc (Martinez Garrido et al., 2016).

This paper analyses the hydronic heating of the air volume inside the church. The modelling allowed to identify the airflows patterns that are generated and theirs effect on the interior finishes as well as the thermal comfort of the churchgoers. The interior temperature that the heating system generate inside the interior volume has been evaluate as well (Liu J.et al., 2012 Napp, 2015).

The church has been evaluated in a $3 \mathrm{~d}$ environment in Autodesk Inventor, as faithfully as possible based on the construction plans. From Autodesk CFD the building has been exported in Autodesk CFD 2018 for further analysis (Figure 3.a, 3.b). In this stage has been define the materials for all the surfaces that form the indoor heating volume. For all the surface have been imposed the limit condition. The exterior walls have a thermal resistance of $\mathrm{R}=1.8 \mathrm{~W} / \mathrm{m}^{2} \mathrm{~K}$ and the outside temperature is taken for measurements made outside during winter that has a maximum of $\mathrm{T}=-18^{\circ} \mathrm{C}$ (Figure 3.c). Also the discretization have been made at a step of 0.5 meters resulting 4 million of elements (Figure 3.d).

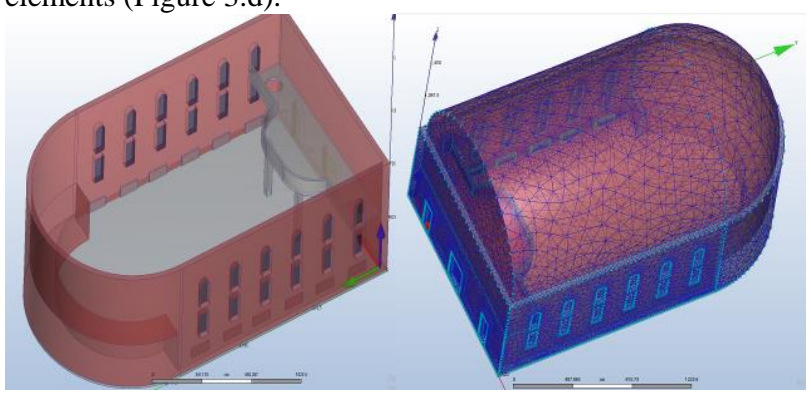

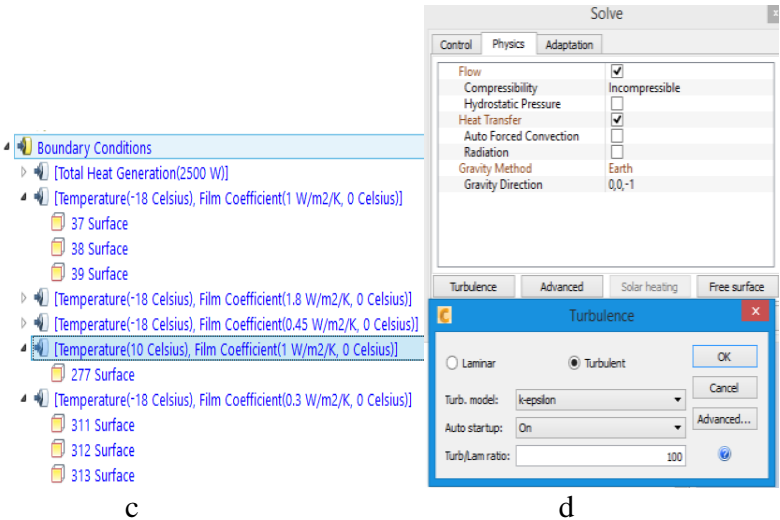

Figure 3. a) Defining the materials for the surface that form the interior volume b) Discretization of the interior volume c) Imposing the boundary conditions d) Defining the turbulence model along others parameters for running the analysis

For numerical simulation of the indoor climate as well as for all simulations it is important to reduce numerical errors. Therefore, for volume simulations, meshing refinements were made by minimizing the size of the elements to achieve constant meshing (Baratasz et al., 2007, Torres and Freitas, 2007).

The transfer equations between the wall and the volume of air is solved by the k-e model equation at the wall, being the scalar equation type (Camuffo et.al. 2014, Camuffo et al. 2010).

\section{CONCLUSIONS}

Hydronic heating system works on the basis of natural convection in large proportion (90\%). The air enters the bottom, is heated due to the buoyancy phenomenon and it comes out at the top (Figure 4a, b).

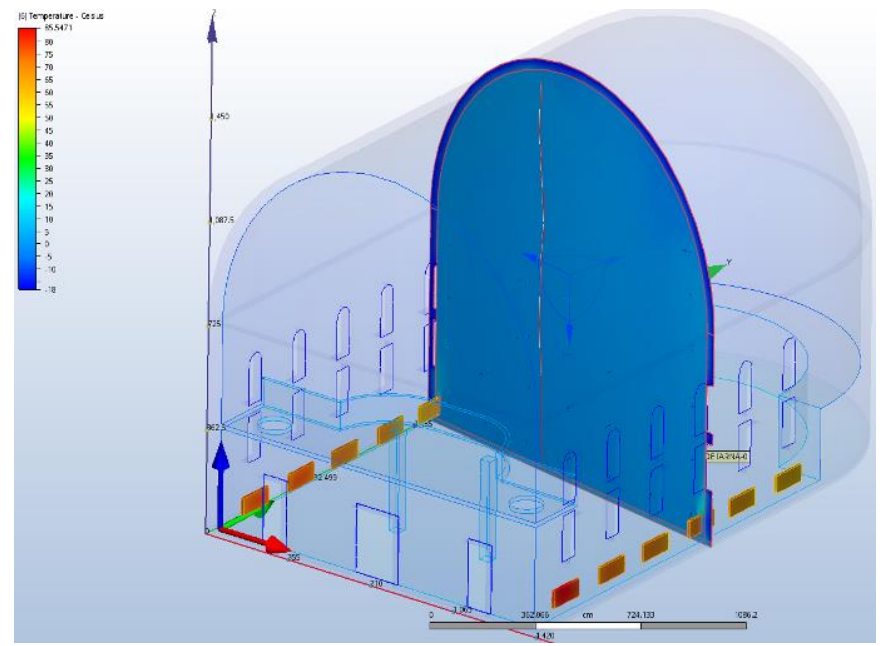




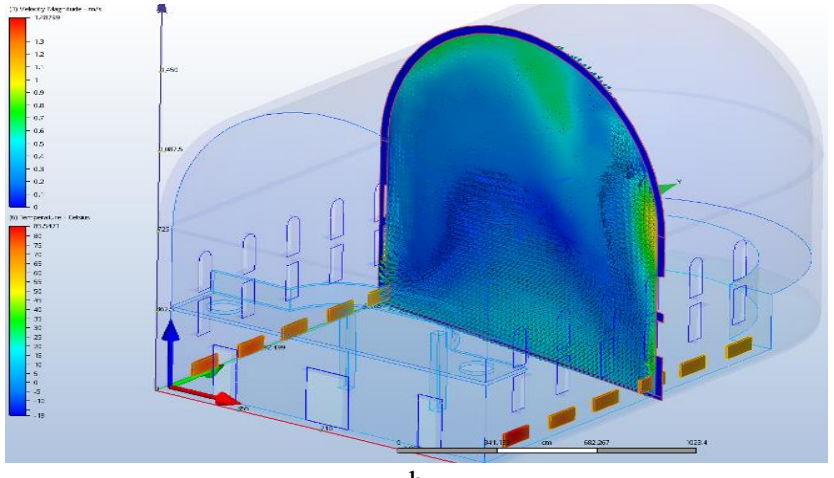

b.

Figure 4. a) Temperature in a transversal section plane b) Air velocity and temperature along a transversal plane
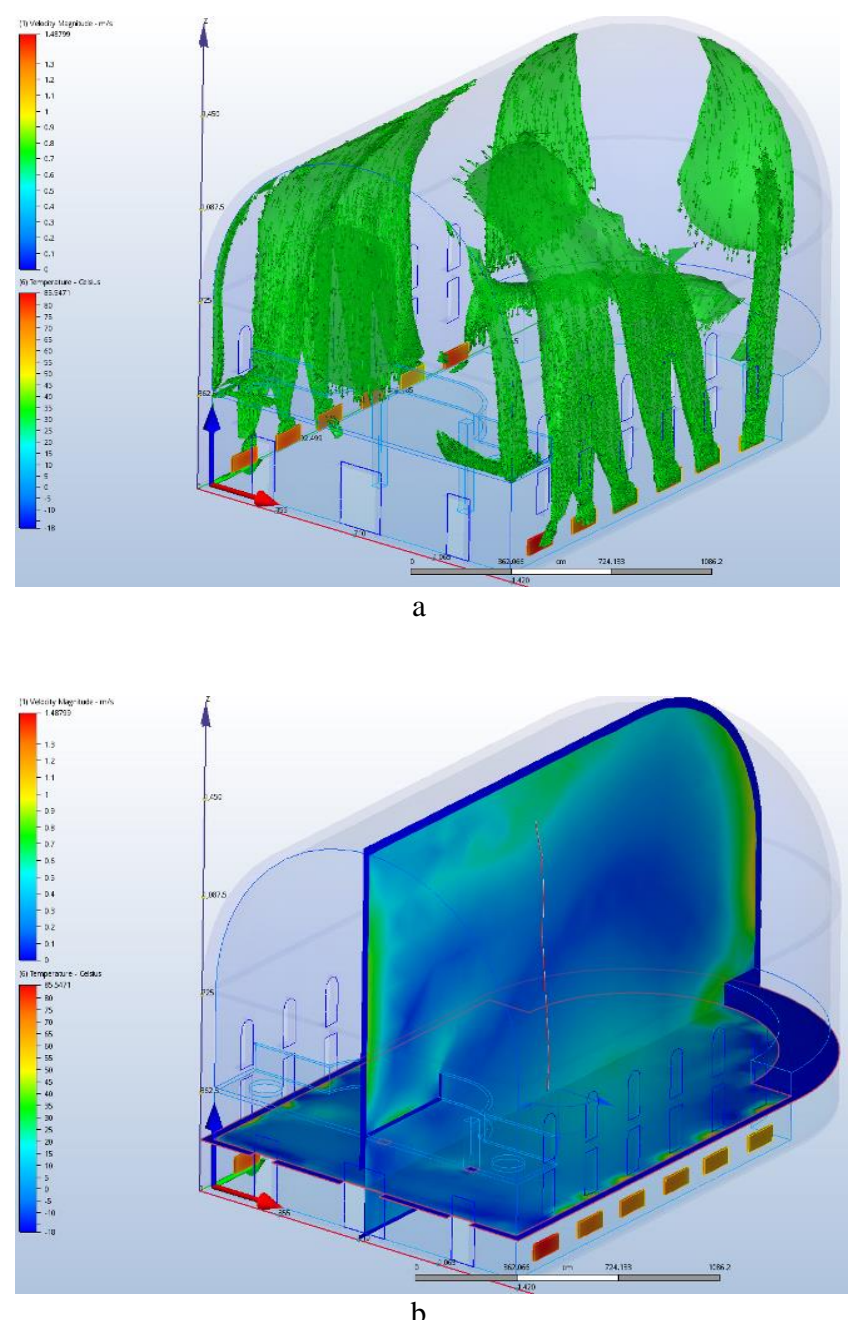

b

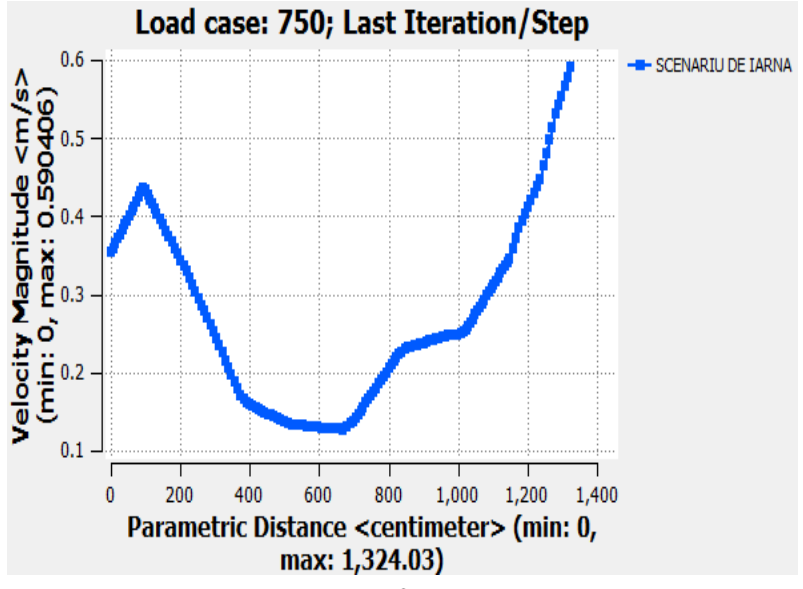

$\mathrm{c}$

From the point of view of the internal thermal comfort, the system is efficient when is used without interruption (Figure 5 $a, b, c)$, but also when the number of radiators is enough and the temperature of the heated volume is homogeneous, especially for small volumes of air.

From visual point of view the hydronic heating system brings discomfort both through the heating bodies and the pipes that are connected to each other and with the boiler.

\section{References}

Bratasz L., Kozlowski, R., Camuffo D., Pagan E., 2007: Impact of indoor heating on painted wood: Monitoring the altarpiece in the church of Santa Maria Magdalena in Rocca Pietore, Italy. Stud. Conserv., 52, pp.199-210.

Camuffo, D., Pagan, E., Schellen, H. \& Limpens-Neilen, D., 2014. A practical guide to the pros and cons of the various heating systems with a view to the conservation of the Cultural Heritage in Churches. Results of the European Project Friendly Heating EVK4-CT-2001-00067, s.1.: s.n.

Camuffo, D., Pagan, E., Rissanen S, Bratasz L.,2010, An advancedchurch heating system favourable to artworks, Journal of Cultural Heritage 11 (2), pp.2015-219.

Jung-Yoon K., Chao-Hsien C., Sang-Moon S., 2014, ISSAQ an integrated sensing systems for real-time indoor air quality monitoring, IEEE Sensors Journal, 14(12), pp.4230-4244.

Liu, J., Yao, R. \& McCloy, R., 2012. A method to weight three categories of adaptive thermal comfort. Energy and Buildings, 47, pp. 312-320.

Martinez Garrido, M. I., Fort, R. \& Varas Muriel, M. J., 2016. Sensor-based monitoring of heating system effectiveness and efficiency in Spanish churches. Indoor and Built Environment, 21(1), pp. 156-165.

Napp M.,Kalamees T., 2015, Energy use and indoor climate of conservation heating, dehumidification and adaptive ventilation for the climate control of mediaeval church in a cold climate, Energy and Buildings, 108, pp.61-71. 
Schellen, H.; Lambertus H. 2002: Heating Monumental Churches - Indoor Climate and Preservation of Cultural Heritage. Eindhoven (NL): Technische Universiteit Eindhoven.

Șen, Z., 2008. Solar energy fundamentals and modelling techniques: atmosphere, environment, climate change and renewable energy. London: Springer-Verlag Limited.

Silva H., Henriques F., 2014, Microclimatic analysis of istoric Buildings - a new methodology for temperate climates, Building and Environment, 82, pp.381-387.

Torres M.I., Freitas V.P, 2007. Treatment of rising damp in historical buildings: wall base ventilation. Build. Environ. 42(1), pp.424-435.

Varas Muriel, M., Martinez Garrido, M. \& Fort, R., 2014. Monitoring the thermal-hygrometric conditions induced by traditional heating systems in a historic Spanish church (12th16th C). Energy and Buildings, 75(3), pp. 119-132.

Vuerich E., Malaspina F., Barazutti M., Georgiadis M., 2008, Indoor measurements of microclimate variables and ozone in the church of San Vicenzo, Italy, Microchemical Journal, 88 (2), pp.218-223. 